\title{
Research and Innovation Processes revisited - Networked Responsibility in Industry
}

\begin{tabular}{|r|l|}
\hline Journal: & Sustainability Accounting, Management and Policy Journal \\
\hline Manuscript ID & SAMPJ-04-2015-0023.R6 \\
\hline Manuscript Type: & Research Paper \\
\hline Keywords: & $\begin{array}{l}\text { Responsible Research and Innovation (RRI), Corporate Social Responsibility } \\
\text { (CSR), notion of responsibility, social desirability, research and innovation }\end{array}$ \\
\hline \multicolumn{2}{|l}{} \\
\hline
\end{tabular}

\section{SCHOLARONE ${ }^{\text {m }}$ \\ Manuscripts}


Purpose - The purpose of this paper is to explore how relationships between different actors are being shaped, in order to allow industry to come to acceptable and desirable uses of Research and Innovation (R\&I) that address societal challenges.

Design/methodology/approach - Building on existing notions of responsibility proposed in the literature, the paper develops a theoretical account of "networks of responsibility" which capture the interlinked nature of responsibility relationships. The usefulness of the approach is evaluated by exploring two cases of R\&I in industry deploying a qualitative research approach that involves interviewing and document analysis. For this, a multinational company from Germany was involved, as well as a small and medium-sized company from Denmark.

Findings - The study surfaced 68 responsibility relationships involving a range of different objects, subjects, authorities, and norms. By describing overlaps in objects, subjects, and other aspects across relationships, the theoretical model proved adequate in untangling and displaying interrelatedness of responsibilities. Furthermore, the analysis surfaced characteristics of Responsible Research and Innovation (RRI) that are already in place in the R\&I processes of two innovative companies, such as anticipation, foresight, and stakeholder engagement. Not all aspects of responsibility outlined in the theoretical model could be extracted from the interview data for every responsibility relationship, pointing to the need for further research.

Originality/value - The paper offers a novel theoretical approach to understanding and analysing responsibility allocations in R\&I in industry. It demonstrates the reliability of this theoretical position empirically. It is practically important because it supports policy development on an organisational as well as societal level.

Keywords: Responsible Research and Innovation (RRI), Corporate Social Responsibility (CSR), notion of responsibility, social desirability, innovation processes

Paper type: Research paper

\section{Introduction}

Over the last few years Responsible Research and Innovation (RRI) has been gaining attention both in the realm of politics and in academia (see among others: Von Schomberg 2012; Murphy et al. 2016; Grunwald 2011; Geoghegan-Quinn 2012). RRI aims to achieve societally desirable outcomes and market products of innovative processes (Von Schomberg 2012). Its emergence reflects the diagnosis that available approaches to shape science and technology still do not meet all of the far-ranging expectations (Siune et al. 2009; Grunwald 2014). RRI combines and embeds existing approaches such as technology assessment (TA), social-technical integration (STIR) and science and technology studies (STS). RRI adds a new element to governance by holding R\&I actors co-responsible for taking societal embedding and potential impacts into account (Fisher \& Rip 2013). R\&I thus becomes a key factor for enabling smart, sustainable and inclusive growth as is aimed for by the European 2020 strategy (European Commission 2010).

Thus far the emergent concept of RRI is predominantly discussed in the context of publicly funded research and innovation (see European Commission 2011; Von Schomberg 2013; Owen et al. 2012). | Privately funded research remains underrepresented (Scholten \& Blok 2015) despite the fact that a large proportion of innovation is undertaken in the private sector (Boroush 2010). Moreover, a number of current EU policies aims to ensure that industry-related research and innovation activities pursue at least the aspects of RRI (Cagnin et al. 2012; European Commission 2011a). 
When applied to business, RRI can be understood as a further elaboration and specification to the existing body of work on Corporate Social Responsibility (CSR) and sustainability accounting. Whereas CSR targets the responsibility of private organisations to consider societal impacts in general (Stohl \& Stohl 2010), RRI focuses on a specific group of responsibilities that are related to R\&I processes within those organisations (Jacob et al. 2013). As such, characteristics of CSR like ethics and stakeholder engagement also appear in RRI. However, RRI also adds more characteristics to the mix or at minimum accentuates pre-existing ones, for example, reflecting on social responsibilities of researchers and anticipating future impacts of R\&I (latridis \& Schroeder 2016). Especially for companies that are in the business of innovation, the argument that RRI should be a core component of CSR applies (Heersmink \& Oosterlaken 2009). Likewise, the integration of societal and sustainability issues into operational practices within organisations addressed by RRI (Stahl \& Brem 2013), has been largely ignored in the extant literature in the field of sustainability accounting (Adams \& Larrinaga-González 2007). For these reasons, it is necessary to explore the (potential) need and possibilities for RRI in industry.

The current discourse surrounding RRI draws on numerous theoretical positions but so far fails to develop a specific account or to demonstrate in which way RRI is different from previous research and innovation governance. One important theoretical root of RRI is the theory of responsibility. It has been suggested that RRI should explicitly link Research and Innovation (R\&I) to responsibility (Owen et al. 2013; Grinbaum \& Groves 2013; Grunwald 2011). However, at present, no such theoretical account of responsibility in RRI exists. Moreover, as we will show below, traditional theories of responsibility tend to focus on individual instances of responsibility. While valuable for understanding responsibility, such individualistic theories fail to reflect the complex and multifacetted reality of modern research and innovation ecosystems. This paper overcomes this gap by developing a new concept of RRI as a meta-responsibility that governs existing networks of interlinking responsibilities. This important theoretical contribution allows the linking of RRI with other theories of research and innovation governance. It also provides the theoretical basis for practical recommendations.

We demonstrate the empirical validity of this novel theoretical approach by empirically mapping existing responsibilities in two case studies. Through this approach, gaps can be located in current practice with regards to the aims and requirements set by RRI, such as considering societal and ethical needs. In this way, the theoretical account facilitates understanding of the need and potential related to RRI in particular R\&I practices. Moreover, through these insights the account points the way to possible practical responses and policy interventions in specific cases.

The paper starts by conceptualising RRI as a higher level or meta-responsibility. This allows reflecting on the ascription of responsibilities in $R \& I$ practice in a procedural manner, i.e. without imposing any societal or ethical norms beforehand. Next, building on existing notions of responsibility, a theoretical account of "networks of responsibility" is developed which captures the interlinked nature of responsibility relationships. It is proposed that the theory of networks of responsibility allows a fine-grained assessment of responsibilities in R\&I practice by mapping existing responsibilities. By allowing an in-depth insight into the distribution and relationships of responsibilities, it also can be used within companies to analyse and improve their accountability for societal and sustainability performance.

The contribution of this paper is twofold: on the one hand, it offers a novel conceptualisation of RRI as a network of responsibilities. This moves beyond the current discourse on RRI and paves the way for both deeper insights and practical guidance on how RRI can be implemented, but it also points to some structural limitations of RRI. On the other hand, the paper provides an empirical account of R\&I processes in two innovative companies, which demonstrates the validity of the conceptual framework. This empirical account demonstrates the relevance of RRI in more traditional areas of 
industry, which are nonetheless driven by innovation and therefore require ways of translating RRI principles into everyday organisational practices.

\section{Conceptual Framework}

This section starts by describing the concept of RRI as a meta-responsibility, which allows us to assess responsibilities in $R \& \mid$ practices taking their contribution to societal acceptability and desirability into account. To be able to reflect on responsibilities in R\&I practice, a conceptualisation of responsibility is needed. Therefore, following an overview of the extant literature, we argue for understanding responsibility as a relationship. Moreover, due to their distributed and entangled nature, responsibilities are hard to allocate and endorse unambiguously (Broadbent et al. 2013). Lastly, to do justice to this complexity surrounding responsibility, we suggest these relationships must be understood as constituting a network of responsibilities.

\subsection{RRI as Meta-Responsibility}

Responsible Research and Innovation (RRI) is a relatively novel concept the meaning of which is still far from fixed or stable (Fisher \& Rip 2013). The probably most widely used definition of the term was suggested by Von Schomberg (2011) who sees it as "a transparent, interactive process by which societal actors and innovators become mutually responsive to each other with a view on the (ethical) acceptability, sustainability and societal desirability of the innovation process and its marketable products (in order to allow a proper embedding of scientific and technological advances in our society)" (p. 9). What this definition shares with other accounts of RRI that have been forwarded over the last decade is the emphasis that it places on the overall objective of RRI, which is to ensure the societal acceptability and desirability of both R\&I processes and products (Timmermans \& Stahl 2013).

Despite the relative novelty of the term itself, it is important to note that RRI can draw on a long history of activities. These include an array of options and methods that aim to clarify possible consequences of R\&I activities, such as risk assessment (Kastenhofer 2011), technology assessment (Grunwald 2009) or other types of ethics or impact assessments (Wright et al. 2011). Attempts to come to a better understanding of possible futures that inform the different types of assessment can be found in technology foresight (Martin 2010; Georghiou 2008) and other types of future studies (Sardar 2010).

RRI exhibits a novel feature that is central to this paper: it explicitly links R\&I to responsibility (Owen et al. 2013; Grinbaum \& Groves 2013). More specifically, it suggests that actors across the innovation eco-system have co-responsibility for considering the broader implications of R\&I (Fisher \& Rip 2013; Owen et al. 2013; Stilgoe et al. 2013). This allows shifting the focus to open up new horizons on how to conduct R\&I. This does not necessarily mean that RRI requires new approaches. Instead, the major novelty of RRI is the integration of existing approaches such as research ethics and social sciences in a novel way by shifting focus and placing new emphases (Grunwald 2011). Additionally, RRI entails new insights into how existing approaches can be embedded "in a day-to-day operational context (i.e. implementation and practice)"(Owen \& Goldberg 2010, p. 1700).

It is beyond the scope of this paper to engage in the discourse on RRI in more depth. We hope that the brief introduction suffices to demonstrate that it is a complex concept whose primary interest lies in the fact that it helps organisations and societies make difficult and often contested decisions with regards to R\&I policy. Here, we want to focus on the question how responsibility for broader impacts can be embedded in R\&I practices within industry. In answering this question we build on an account of RRI first forwarded by Stahl (2013) that understands RRI as "a higher level responsibility or meta-responsibility that aims to shape, maintain, develop, coordinate and align existing and novel 
research and innovation-related processes, actors and responsibilities with a view to ensuring desirable and acceptable research outcomes" (p. 1).

This view acknowledges that RRI does not enter an empty playing field. Actors in the realm of R\&I already have multiple responsibilities, for instance, in their roles as researcher, developer, manufacturer or manager. Rather than adding yet another responsibility, RRI is based on a number of already existing responsibilities and its novelty and practical relevance is in the fact that these are treated as a whole that needs to be addressed in order to lead to desirable outcomes. RRI, therefore, entails a higher level responsibility to make sure that responsibilities ascribed at a lower level, i.e. by actors within R\&I processes, are in alignment with societal goals and desires. RRI as a metaresponsibility then necessitates (ethical) reflection on the processes, actors, and responsibilities currently in place in R\&I practice. By reflecting, an assessment is made of the current state of R\&I practice and whether amendments or alterations are required in order for it to become responsible R\&I.

Moreover, unlike other accounts of RRI, because of its procedural nature, RRI as a metaresponsibility does not presuppose substantive claims with regards to the societal norms and values to be included (Stahl et al. 2013). This way it is able to accommodate substantive aspects forwarded by other accounts of RRI such as those by Von Schomberg (2011), Grunwald (2011) and Sutcliffe (2011). For example, it can account for the suggestions by Von Schomberg (2011) that RRI should consider sustainability and ethical issues, and by Stilgoe et al. (2013) that researchers and funders are an appropriate subject of responsibility.

\subsection{The Concept of Responsibility}

If RRI is understood as a meta-responsibility, then an investigation of RRI in industry needs to work with a clear understanding of responsibility. This is a venerable term with a long history of discussion in philosophy and jurisprudence (Hart 1968). In recent decades the term has gained currency as a 'significant new cultural master frame' (Strydom 1999, p.76) connected with risk, complexity, and uncertainty (Pellizzoni 2004; Grunwald 2011; Giddens 2003). In the context of business, for example in relation to CSR and social accountability, it has been invoked as a viable alternative to the waning influence of the state pared to the amplification of corporate power (Sillanpää in: Visser et al. 2010; Pellizzoni 2004). Similarly the concept of responsibility used to address questions of the relationship between R\&I and society (Jonas 1984; Vincent et al. 2011), most recently in the discourse on RRI (Grunwald 2011; Stahl 2012; Owen et al. 2013; Von Schomberg 2013; van den Hoven 2013; Grinbaum \& Groves 2013). Both CSR and RRI ask for economic, social and environmental responsibilities to address all stakeholders' needs throughout the corporate structures and processes (latridis and Schroeder, 2016).

For organisations to take their responsibility or to be held accountable, the availability of information is essential. Substantive mechanisms for organisational accountability, such as sustainability accounting, play a crucial role in "--clarifying the extent to which organisations are addressing (and actually can address) the substantive exigencies of (un)sustainability."'- (Gray 2010, p.17) By auditing and reporting on social and environmental issues and performance (Tilt 2009; Dienes et al. 2016), information flows are managed and provided for internal decision making and to be obtained by external parties such as NGOs (Burritt \& Schaltegger 2010). Furthermore, monitoring the performance of companies supports CSR and RRI by identifying areas for improvement and potential drawbacks (latridis \& Schroeder 2016; Christ et al. 2016). Social and sustainability accounting, therefore, must be regarded as a necessary constituent linked to the rise of the importance of the term responsibility. 
The added value of the use of responsibility in RRI as compared to CSR and sustainability accounting is that it opens up the range of relevant actors (here termed the subject see below). Whereas extant CSR and accounting literature predominantly addresses responsibilities of actors on an aggregate level such as corporations (Schwartz \& Carroll 2003), companies (Murray et al. 2010) or enterprises (European Commission 2011a), or of managers or executives representing such actors (Albelda 2011; Windolph et al. 2014; Dienes et al. 2016), RRI also targets responsibilities of (groups of) individuals that compounded actors are made up of, such as researchers, innovators, and policymakers (Grunwald 2011; Fisher \& Rip 2013; Stilgoe et al. 2013).

Apart from its relevance to RRI, by increasing the adoption and promotion of corporate social and environmental responsibility, a detailed understanding of individual responsibilities is also of value to CSR and sustainability accounting. On the one hand, it provides an additional mechanism to holding corporations responsible for their claims and actual performance regarding social and environmental issues. On the other hand, it supports accounting processes by providing further insight into what knowledge is needed by (individual) organisational members to take their social responsibility and what relevant information they can contribute to social and environmental reporting and management.

To be able to discuss responsibilities on an individual level we posit that at the heart of responsibility there is a relationship between something or someone that is responsible (the subject of responsibility) and something or someone that the subject is responsible for (the object of responsibility) (Lenk \& Maring 2001). Objects may include actions, results of actions, tasks and states of affairs, but also subordinates or parts of organisations (Grunwald 2011; Stahl 2004).

Responsibility comes from "response", from answerability (Pellizzoni 2004; French 1979). It, therefore, is related to communication structures that provide a broader context of responsibility relationships. The link between the subject and the object is supported by what we call an authority, which oversees the responsibility and attributes sanctions to the subject (Lenk 2006). The following figure demonstrates this basic model of responsibility.

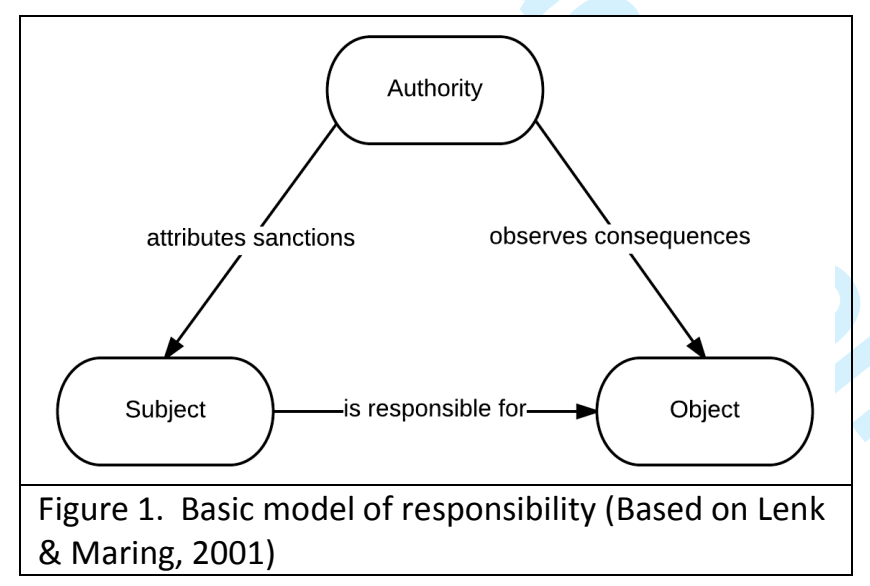

Responsibility relationships are not natural occurrences but they are the outcome of negotiations and represent social ascriptions (Grunwald 2012). This means that the subject is ascribed responsibility for the object. Such an ascription can happen transitively (i.e. it is ascribed to the subject by an external body) or reflexively (i.e. the subject assumes responsibility for the object). Ascription can be consensual or contested and conflictual. To demonstrate the point, let us imagine a researcher as the subject and the quality of her research project as the object. The responsibility of the researcher for her research quality can be assigned by her organisation, a professional body that she is a member of (both transitive) or by herself (reflexive). Authorities overseeing this responsibility 
could be of a legal nature, for instance when she is held legally responsible for faults of the product, but could also be her own conscience or her peers. She could be attributed negative sanctions, for example, a fine or demotion or positive ones such as a bonus or praise from her organisation.

We believe that the purpose of responsibility is to facilitate social coordination with a view to achieving a desirable state, like frugal and reverse innovation (Brem \& Ivens 2013). It may be possible to find exceptions to this rule, but the majority of responsibility relationships that are defined and that actors are aware of in the area of R\&I conform to this scheme of subject, object, authority and the underlying aim of improving the status quo.

To represent this underlying aim, we add a further element to the basic model, namely the 'norm' to be met by the subject by taking responsibility. 'Norm' is understood here to represent the prescriptive criteria such as standards, principles, values, customs or norms (Lenk \& Maring 2001; Grunwald 2011), to which the subject has to accord to when taking responsibility or being held responsible for the object. This way the model not only allows us to analyse who is responsible for what in the face of an instance of judgement within R\&I processes, but also how societal acceptability or desirability are represented within this responsibility.

In addition to the three elements of the basic model and norm, another feature that is important to our current endeavour is the temporal dimension (Ricoeur 1992; Vincent 2011). Responsibility can be ascribed for future objects, for example, when a researcher is held responsible for the reliability of the product to its users, as well as for past actions, for instance, in the case of a malfunction of an innovative artefact. Because R\&l is steeped in uncertainty the forward-looking or anticipatory view of responsibility is regarded as more appropriate for RRI (Pellizzoni 2004; Grinbaum \& Groves 2013; Stahl et al. 2013; Lee \& Petts 2013). Backward-looking responsibilities, such as accountability and liability, rely too heavily on our ability to "reasonably foresee" or predict consequences of our actions (Pellizzoni 2004; Stilgoe et al. 2013). Our current investigation, therefore, focuses on forward-looking responsibilities.

However, even if this principle is accepted, it is important to note that each of the components in this model is subject to extensive debate. This paper captures some of these to demonstrate the complexity of any individual responsibility ascription.

For example, a key question in the theory of responsibility is whether only rational adult human beings can be subjects of responsibility or whether other entities from corporation and groups (French 1972) to technical artefacts (Floridi \& Sanders 2004) can be subjects. This links to the question which conditions a subject needs to fulfil in order to be eligible to be a subject. Examples of necessary conditions for the ascription of responsibility to a subject include a causal influence from the subject on the object (Goldman 1999), freedom of will and action that allows the subject to exert the causal influence on the object (Fischer 1999) and a number of personal qualities (Wallace 1998) that range from self-control, emotional stability and an ability to react appropriately to external stimuli to education and self-control. It should be obvious that these touch on a number of problematic philosophical and anthropological assumptions and positions that this paper cannot discuss in depth. For current purposes, our analysis, therefore, is limited to discerning individual and collective actors that are attributed responsibility within the R\&I processes.

The authority raises similarly fundamental questions. In some cases, the authority in a responsibility relationship is clearly defined, for example in legal responsibility. In other cases, authorities might include a person's conscience, which could be more contested (Lenk 1997). The nature of the authority has direct knock-on effects for the type of sanctions that can result for the subject on the basis of a responsibility ascription. 
Also, the normative basis gives rise to such considerations. Depending on the type of responsibility and the type of authority, there are different normative foundations of responsibility relationships (Lenk \& Maring 2001). They converge on the principle that ascribing responsibility is meant to make a positive difference. What would constitute such a positive difference and how it could be perceived is partly dependent on the normative foundations. These can be the law, they can be moral traditions and norms, and they could be professional standards or codes of conduct, to name some prominent examples (Grunwald 2011). Because RRI revolves around societal desirability and acceptability of R\&I, the norms that underlie responsibility ascriptions are included in the current analysis.

This brief discussion of relevant possible aspects and dimensions that can influence responsibility relationships does not claim to be comprehensive. It shows, however, that any individual example of a responsibility relationship can be highly complex and requires extensive negotiation and is context specific. In many cases, these negotiations are undertaken on a higher level not directly related to the individual responsibility, for example when legal liability is defined that then gets applied to a specific example.

While the discussion of these components shows the complexity and multiplicity of influencing factors and dimensions of responsibility relationships, we feel that it still fails to represent the complexity of real-life responsibilities. We argue that any individual responsibility is always embedded in larger networks of responsibility.

\subsection{Networks of Responsibility}

The theoretically relevant point that we would like to make here is that responsibility is not a singular phenomenon. The majority of the literature on responsibility looks at particular types or examples of responsibilities and then focuses on a particular aspect. This tends to lead to the crowding out of the fact that responsibilities are always multiple and networked. For example, a researcher who is the subject of professional responsibilities towards her clients can have moral and legal parental responsibilities for her children and moral and legal responsibilities for her conduct as a citizen. An instance of multiple responsibilities by one subject is shown in the next figure.

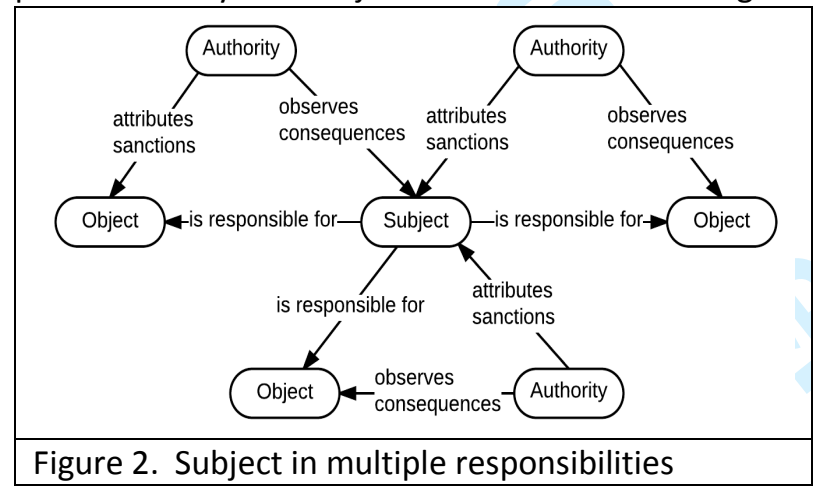

To complicate matters further, the interrelationship between the different components of responsibility relationships goes far beyond this simple case where one subject has multiple responsibilities. The subject of responsibility may be an object of responsibility in another relationship and the authority in a third one. Our researcher may be the object of responsibility of her employer and she may serve on a jury in a trial about scientific misconduct, thus acting as an authority in another instance of responsibility. To make matters even more complicated, responsibilities may be reciprocal or overlapping. Our researcher may be a member of a group of concerned scientists who collectively assume responsibility for certain developments and she may be an employee of a company that is held responsible for scientific misconduct. 
Similarly, there may be responsibilities for entire responsibility relationships. A responsibility relationship may be the professional responsibility of a researcher for the fulfilment of requirements. This may be overseen by a professional body and lead to sanctions such as the expulsion of the subject in case of gross negligence. This entire relationship may be the object of responsibility of an external agency, such as a regulatory body overseeing professionalism in a particular sector. This might be represented as follows:

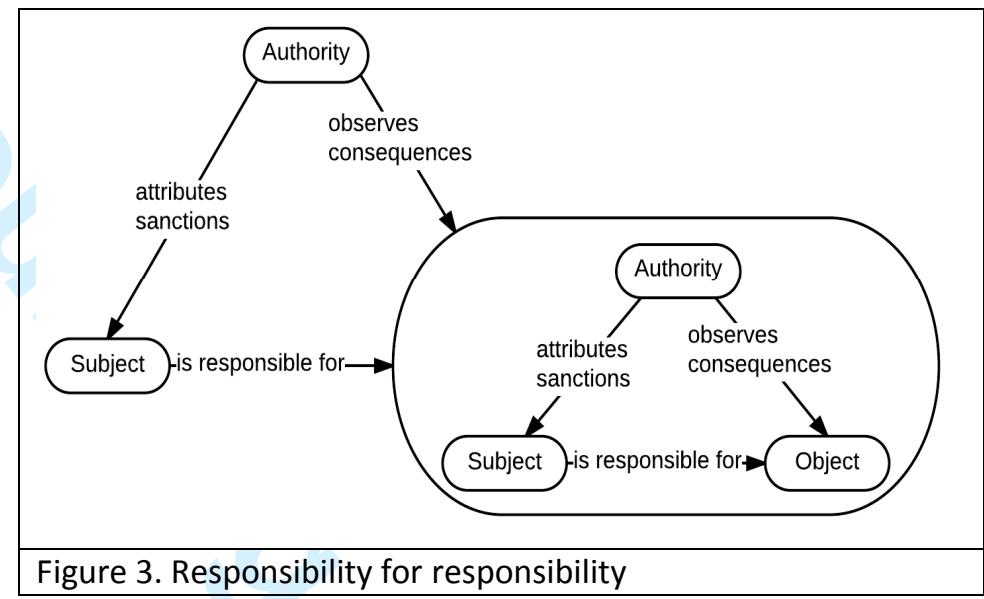

Networks of responsibility govern individual behaviour to a significant degree. They offer incentives for certain types of behaviour and they dis-incentivise other actions. They incorporate the different normative regimes in which any agent always acts. Networks of responsibility are sociotechnical ensembles that are enacted by a multitude of actors.

Coming back to the overall research question of this paper, we now have the conceptual and theoretical basis to think about the question how R\&I can contribute to the resolution of societal challenges. If our initial position is correct that RRI is a means to align responsibilities to allow R\&I to address societal challenges, then we can now ask how and to what extent this is currently the case and can be observed. The following section presents a methodology and findings of a study that aimed to find out the current state of responsible innovation in industry.

\section{Meta-Responsibility in Practice}

In order to explore the connections between the subject, the object and the authority within networks of responsibility, a study was undertaken following a purposive selection logic on finding cases that assists in establishing robust results on illustrating the theory of networks of responsibility (Patton 2002; Hine \& Carson 2007). This research approach builds on the interpretive tradition (Walsham 1993; Klein \& Myers 1999; Walsham 2006). Its aim is exploratory and it seeks to understand how actors in the field of R\&I view their activities and make sense of it. The purpose of this research is thus to understand in a hermeneutic sense rather than to explain in a nomothetic sense (Butler 1998). This position in the continuum of research paradigms (Chen \& Hirschheim 2004) explains the choice of methodology in both data collection and data analysis.

The selected cases underlying this study consist of an innovative multinational corporation (MNC) located in Germany, specialising in instruments for creative expression, anonymously called CREACorp, and a Danish small- and medium-sized enterprise (SME), providing products and services within the field of welfare technology, anonymously ${ }^{\underline{1}}$ called AGE-Comp. CREA-Corp operates globally, has

${ }^{1}$ For reasons of anonymity, the real names of the companies used as cases are not provided. 
3000 employees and an annual turnover of 250 million euro (2010). Having existed for over a century, CREA-Corp is a well-established brand, selling its innovative products world-wide to both industry as well as consumers. In contrast, AGE-Comp, as a company in the domain of information and communications technology (ICT), operates on a national level and has fewer than 50 employees. AGE-Comp has more than seven years of experience in providing customised solutions to nursing homes, caregivers, and elderly people. The company offers a software platform that supports the optimisation of the workflow of caregivers and improves communication between caregivers, elderly people, and their relatives.

Selecting two cases that differ in geographical location, size, and type of industry, was important because it allows us to identify common patterns across different responsibility networks in industry. Hence, our approach follows the idea of Yin (2009) of finding "an extreme or a unique case" (p.47) which offers the potential for generalisations. Search criteria for the companies were the geographical location (Germany/Denmark), size (MNC/SME) and operating in different industries. In addition, a notable involvement with Corporate Social Responsibility (CSR) was required. Both companies fulfil these requirements in different ways. CREA-Corp has a professional CSR management and has developed a CSR strategy beforehand. This is implemented in the whole organiszation, from supply to production and commercialization. AGE-Comp's aim is to develop tools that support the elderly and people with cognitive handicaps to become more independent in their everyday life. This way the company seeks to contribute to tackling some of the grand challenges namely health, demographic change and wellbeing. This focus on societal challenges makes AGEComp a suitable case for this study.

\subsection{Methodology}

The data for this study were collected by interviewing employees of the two companies using semistructured interviews and by conducting document analyses of company documentation. The interview schedule was structured according to concepts in the theoretical account of responsibility outlined above. Furthermore, the schedule was enhanced by studying general information about the companies available online. Interviews were conducted either face to face or via telephone and lasted between 1/2 and 1 hour. Data collection took place in 2014 for CREA-Corp and in 2015 for AGE-Comp. The overall number of interviewees for the study is 12 , which were completed in three rounds engaging 7 interviewees.

The interviewees from CREA-Corp are part of the R\&D department of the company and therefore directly involved in R\&I practice. Interviewee 1 is the leader of one of the three R\&D teams, while interviewee 2 is head of the R\&D department. AGE-Comp does not have a departmental structure like CREA-Corp. For this case, interviewees, therefore, were recruited throughout the company: the chief executive officer (CEO), the chief technology officer (CTO), a project manager, an interactive designer, and a digital designer.

Before analysing them, the interviews were fully transcribed. Data analysis was undertaken using the qualitative data analysis software $N V_{i v O^{2}}$, version 10 . Data were coded using thematic analyses (Miles \& Huberman 1994). Initial codes were identified from the literature on responsibility and RRI. These included the components and dimensions discussed above. The complete initial list of top level codes includes subjects of responsibility, objects of responsibility, authorities, and norms. During the coding of the data interesting findings were noted in separate memos that captured specific insights and that were used to formulate theoretical hypotheses of interest for further coding.

\footnotetext{
${ }^{2}$ http://www.qsrinternational.com/products nvivo.aspx
} 


\subsection{Findings}

By implementing the conceptual framework on the two cases, responsibility relationships were identified from the data in terms of the constitutive elements: subject, object, authority and norm. This way, 68 responsibility relationships emerged from the data collected: 36 for CREA-Corp and 32 for AGE-Comp. For example, an interviewee stated that "university students do graduate work in the company such as examine special topics and basic technology development". Based on this, "university" was designated as a subject, with "basic research" as its object in a responsibility relationship.

However, not every element of responsibility relationships emerged from the data for every relationship. Whenever possible, this was remedied by extrapolating from the data what this element most likely would be, otherwise, elements are left open. In the example above, for instance, "peer reviewers/academia" are extrapolated as an authority with "academic standards" as the norm. In contrast, in a responsibility relationship with subject "R\&D co-worker" and object "foresight", the elements norm and authority were left blank.

Below the different elements of responsibility relationships and the networks they constitute are discussed for the two companies: first the objects and norms, and second the actors in their role as subjects, objects, and authorities in responsibility relationships.

\subsubsection{Objects and Norms in Responsibility Relationships}

From the data collected, in total 60 objects and/or norms of responsibility emerge that represent an activity or a result of an activity: 31 for CREA-Corp, and 28 for AGE-Comp (see table 1). To establish which of the existing responsibilities are relevant to RRI, objects and norms that have a connection with societal acceptability or desirability of R\&I are singled out.

\begin{tabular}{|c|c|c|c|c|c|c|}
\hline & \multicolumn{3}{|l|}{ CREA-Corp } & \multicolumn{3}{|l|}{ AGE-Comp } \\
\hline & Content (action/result of action) & Object & Norm & Content (action/result of action) & Object & Norm \\
\hline 1 & (Future) legislation on chemicals & 1 & & Company' credit & 1 & \\
\hline 2 & Academic standards & & 1 & Software development & 1 & \\
\hline 3 & Apply local standards globally & & 1 & Web development & 1 & \\
\hline 4 & Basic research & 1 & & Elderly people's needs & 6 & 2 \\
\hline 5 & Company framework & 3 & 7 & R\&D project & 3 & \\
\hline 6 & Criteria per gate & & 1 & Dialogue with the clients & 2 & \\
\hline 7 & CSR & 1 & 1 & Project management & 3 & \\
\hline 8 & Customer needs & & 2 & Marketing decisions & 1 & \\
\hline 9 & European norms & 1 & & Review of the project & 2 & \\
\hline 10 & Foresight & 3 & & Release new features of services & 1 & \\
\hline 11 & Legislation & & 3 & Elderly people' relatives & 2 & \\
\hline 12 & Market research & 1 & & Protect IP & & 4 \\
\hline 13 & Market success & 1 & 3 & Market introduction of a service & 1 & \\
\hline 14 & Overall development & 1 & & Legislation & 2 & 4 \\
\hline 15 & Overall research & 1 & & Caregivers income & 2 & \\
\hline 16 & Partnerships & 1 & & Commercialiszing the project & 4 & \\
\hline 17 & Product requirements & 4 & 2 & R\&D product & 1 & \\
\hline 18 & Protect IP & & 1 & Designing new applications & $\mathrm{V}$ & 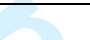 \\
\hline 19 & Product safety & 2 & & Research agenda & 2 & 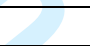 \\
\hline 20 & Process safety & 1 & & Development of services & 1 & $\bar{r}$ \\
\hline 21 & Production process & 1 & & Proof of concept of new features & 1 & \\
\hline 22 & Project management & 1 & & Company success & & 6 \\
\hline 23 & Public mood; Impact of society & & 1 & New services & 1 & \\
\hline 24 & R\&D process & 2 & & International norms & 2 & 5 \\
\hline 25 & R\&D product & 3 & & Basic research & 1 & \\
\hline 26 & R\&D product development & 1 & & Privacy by design & 1 & 2 \\
\hline 27 & Research agenda & 2 & & Elderly people relatives' demands & 3 & 1 \\
\hline
\end{tabular}




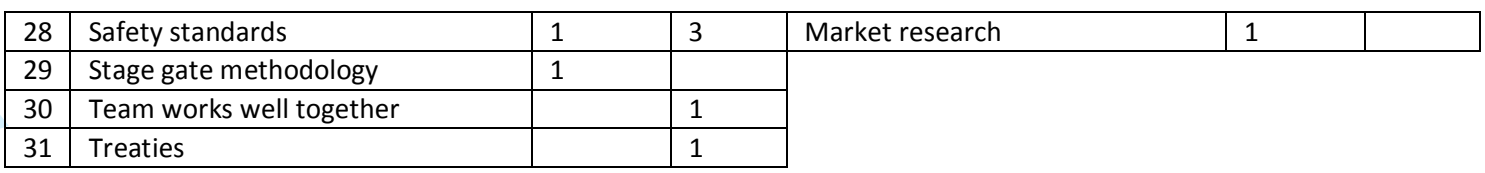

Table 1. Objects and norms per company

Objects were regarded as relevant, either when the object represented an action or the result of the action was related to the overall objective of RRI.

For example, in CREA-Corp "foresight" functions as an object in three different responsibility relationships. Foresight can be understood as an enabler of anticipation, which is a central dimension of RRI (Owen et al. 2013; Von Schomberg 2013). The three responsibility relations ensure that foresight is in place within the company R\&I processes. For example, the interview data states, that methods are being deployed "to gauge the moods of the public" with regards to (future) products and technologies. Among others this is important to secure future compliance with (legal) standards, to preserve public esteem for the company brand built up over the years, and to distinguish products from competitors by going beyond market standards in fulfilling social desires. What's more, going beyond or ahead of current standards is also viewed as a way to differentiate from competitors. Setting more stringent standards for products in compliance with societal desires may entail a strategic advantage over competing products. Also, the company is represented in standards organisations on a national and European level. This way the company stays in touch with developments of standards, which is required to anticipate them, but moreover, is in a position to actively contribute to the directions these developments will take as well. However, in comparison to aspirations set in the RRI discourse, which sometimes talks of future generations (Grinbaum \& Groves 2013), the foresight in the company seems to have a limited time horizon. One interviewee, for instance, indicated that the company wants to be "two or three years ahead" of the introduction of new legislation.

Furthermore, within AGE-Comp, "dialogue with the clients" functions as an object in two different responsibility relationships. By communicating and engaging clients, in particular by getting feedback from elderly people in the design process and product management cycle, AGE-Comp reflects on clients' societal and ethical concerns.

Similarly, norms that are associated with societal desirability or acceptability can be singled out as being of relevance to RRI. For example, for CREA-Corp "public mood" came forward as a norm set to the object "product requirements". Interview data states that public moods are assessed by monitoring current public debates via TV, the Internet and engaging with stakeholders such as universities.

Also for CREA-Corp, the norm "apply local standards globally" emerged from the data. This norm represents the efforts taken by the company to exceed (inferior) local standards in certain countries they operate in by applying the highest local standard among any of the countries the company is active globally. This way the strictest standards are always met irrespectively of the specific locality of the company's operations.

In addition to their function as an object, activities and/or results of activities at the same time function as a norm in further responsibility relationships: in 5 instances for CREA-Corp and 4 in AGEComp (see table 1). AGE-Comp, for example, develops an ICT platform for the elderly that respects the personal privacy of its users. This, for instance, is represented by the object "Privacy by design" to which several subjects, such as the CTO, interactive designer, and digital designer are related. At the same time, privacy also is implicated as a norm related to responsibilities such as monitoring elderly people's life in their homes, and data security in general. Thus, while privacy is a key concern 
of AGE-Comp as an object of responsibility, it also acts as a norm to be met across responsibilities within the company.

In AGE-Comp, "elderly people's needs" acts as an object in 6 responsibility relationships and functions as a norm in two instances. This norm not only represents a societal need, but based on the number of responsibilities related to this norm, it clearly must be regarded as a key element to the success of the company.

Likewise, in CREA-Corp "CSR" emerged from the data both as an object and a norm. CSR, therefore, is viewed as an activity that actors within the company are responsible for, but it also acts as a norm that is to be met by the company. CSR materialises in the so-called "Company framework", which functions as an object in seven responsibility relationships and as a norm in three. The company framework and underlying objects such as "foresight", "safety standards", "process safety", and "product safety" represent responsibilities of actors involved in R\&I towards meeting ethical or social standards. Social and product (safety) standards, for instance, are included in the company framework, and adherence to the framework is viewed as a collective effort on a daily basis (see figure 4). Moreover, the development of the company framework over time is viewed as a companywide responsibility of each "co-worker" in general and actors such as the "internal compliance organisation" and the "head of the R\&D department" more specifically.

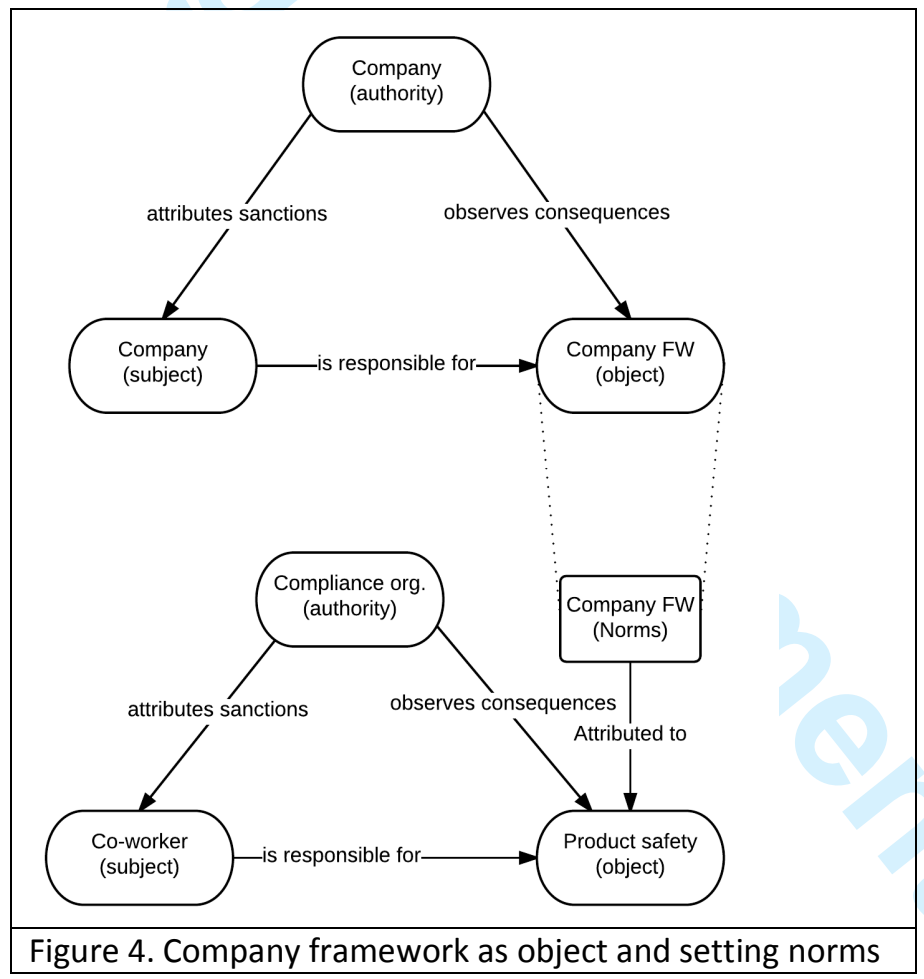

Figure 4 depicts how overarching responsibilities such as CSR are further refined in underlying responsibilities such the company framework, and below it, safety standards. Although not in a formal company framework, also in AGE-Comp, adherence to ethical standards and societal norms is an integral part of the R\&I processes. The norms "international norms" and "legislation" are representative of the way AGE-Comp actively and consistently seeks to include societal concerns into their design and development activities.

In all these examples of the co-occurrence of norms and objects, the actors within the company are responsible for setting norms to further responsibilities themselves. Part of setting norms is 
reflecting on them, which is regarded a key activity of RRI (see, for example, Grunwald 2011; Owen et al. 2013) Also, it shows how different responsibilities within the companies are interrelated: attribution of one responsibility, i.e. adhering to standards, requires discharging of another, i.e. establishing the standard.

\subsubsection{Actors in Responsibility Relationships}

Overall 37 actors related to the R\&I process of the companies emerged from the data: 18 for CREACorp and 19 for AGE-Comp (see table 2 below).

\begin{tabular}{|c|c|c|c|c|c|c|c|}
\hline & Company & Actor & Subject & Object & Authority & Type & Location \\
\hline 1 & \multirow{18}{*}{$\begin{array}{l}\text { CREA- } \\
\text { Corp }\end{array}$} & Company & 4 & & 4 & Collective & Internal \\
\hline 2 & & Co-worker & 3 & & & Individual & Internal \\
\hline 3 & & Evaluation team & 1 & & & Collective & Internal \\
\hline 4 & & $\begin{array}{l}\text { German Chemical Industry } \\
\text { Ass.(VCI) }\end{array}$ & 1 & & & Collective & External \\
\hline 5 & & Head of overall R\&D department & 8 & & 2 & Individual & Internal \\
\hline 6 & & Head of R\&D department & 4 & & 1 & Individual & Internal \\
\hline 7 & & Industrial client / customer & 3 & & & Individual & External \\
\hline 8 & & Internal compliance organisation & 1 & & 6 & Collective & Internal \\
\hline 9 & & Legal authority & & & 5 & Collective & External \\
\hline 10 & & 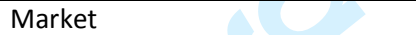 & & & 6 & Collective & External \\
\hline 11 & & Marketing department & 1 & & & Collective & Internal \\
\hline 12 & & Peer reviewers / academia & & & 1 & Collective & External \\
\hline 13 & & R\&D co-worker & 1 & & & Individual & Internal \\
\hline 14 & & R\&D department & 5 & 1 & & Collective & Internal \\
\hline 15 & & R\&D project & 2 & 3 & & Collective & Internal \\
\hline 16 & & Safety department & 1 & 1 & & Collective & Internal \\
\hline 17 & & Society & 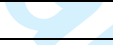 & & 1 & Collective & External \\
\hline 18 & & University & 1 & 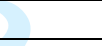 & & Collective & External \\
\hline 1 & \multirow{19}{*}{$\begin{array}{l}\text { AGE- } \\
\text { Comp }\end{array}$} & CEO & 5 & 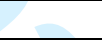 & 7 & Individual & Internal \\
\hline 2 & & СТO & 3 & 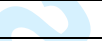 & 4 & Individual & Internal \\
\hline 3 & & IT department & 2 & 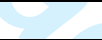 & 3 & Collective & Internal \\
\hline 4 & & Digital designer & 5 & & s & Individual & Internal \\
\hline 5 & & ICT platform & 2 & & 1 & Collective & Internal \\
\hline 6 & & Project manager & 3 & & 1 & Individual & Internal \\
\hline 7 & & R\&D project & 2 & 3 & 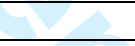 & Collective & Internal \\
\hline 8 & & Interactive designer & 3 & & 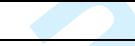 & Individual & Internal \\
\hline 9 & & Commercialized project & 1 & 4 & 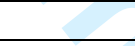 & Collective & Internal \\
\hline 10 & & Company & 4 & & 1 & Collective & Internal \\
\hline 11 & & Care professionals & 2 & & 2 & Individual & External \\
\hline 12 & & Elderly people's relatives & 1 & & 1 & Individual & External \\
\hline 13 & & Society & & & 1 & Collective & External \\
\hline 14 & & Evaluation team & 1 & & & Collective & Internal \\
\hline 15 & & Market & & & 4 & Collective & External \\
\hline 16 & & Elderly people & & 6 & 1 & Individual & External \\
\hline 17 & & Legal authority & & & 8 & Collective & External \\
\hline 18 & & Peer-reviewers & & & 1 & Collective & External \\
\hline 19 & & Investors / shareholders & & & 2 & Individual & Internal \\
\hline
\end{tabular}

Table 2. Actors, the number of actors per element-type, type of actor and location of the actor.

Out of 37 actors, 28 function as a subject in one or more of 36 responsibility relationships. Of these, 16 actors reappeared as a subject of responsibility in multiple responsibility relationships. For instance, the actor "R\&D department" of CREA-Corp is implied as a subject in two different responsibility relationships, while the actor "CEO" of AGE-Comp is implied 5 times. Through these relationships, actors are a subject of responsibility for several objects. For example "R\&D department" is related to the objects "R\&D product" and "Product requirements". 
Having to meet multiple responsibilities may be a cause of conflict to subjects. For example, the norms for the two responsibilities of the "R\&D department", "customer needs" and "company framework", may at times set conflicting demands (see figure 5 below).

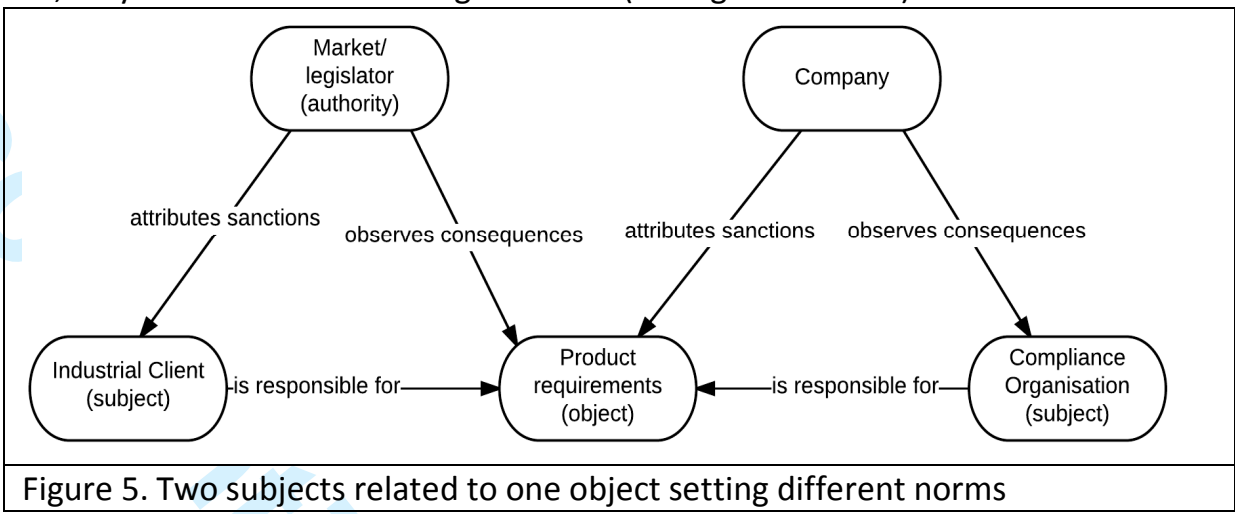

In the same vein, multiple subjects appeared to be responsible for the same object. In AGE-Comp, for example, the actors "СTO" and "digital designer" both are subjects of responsibility for the object "R\&D project". Again, the way the subjects act on their responsibility may give rise to conflicting interests and therefore require alignment.

In addition to serving as subjects of responsibility, 6 actors emerged as an object of responsibility and 22 as an authority in responsibility relationships. This reflects the way actors are organised and management is structured within the companies. In CREA-Corp, for example, the actor "head of an R\&D department" is responsible for an R\&D project on different levels, such as whether the project requirements are met and the team works well together.

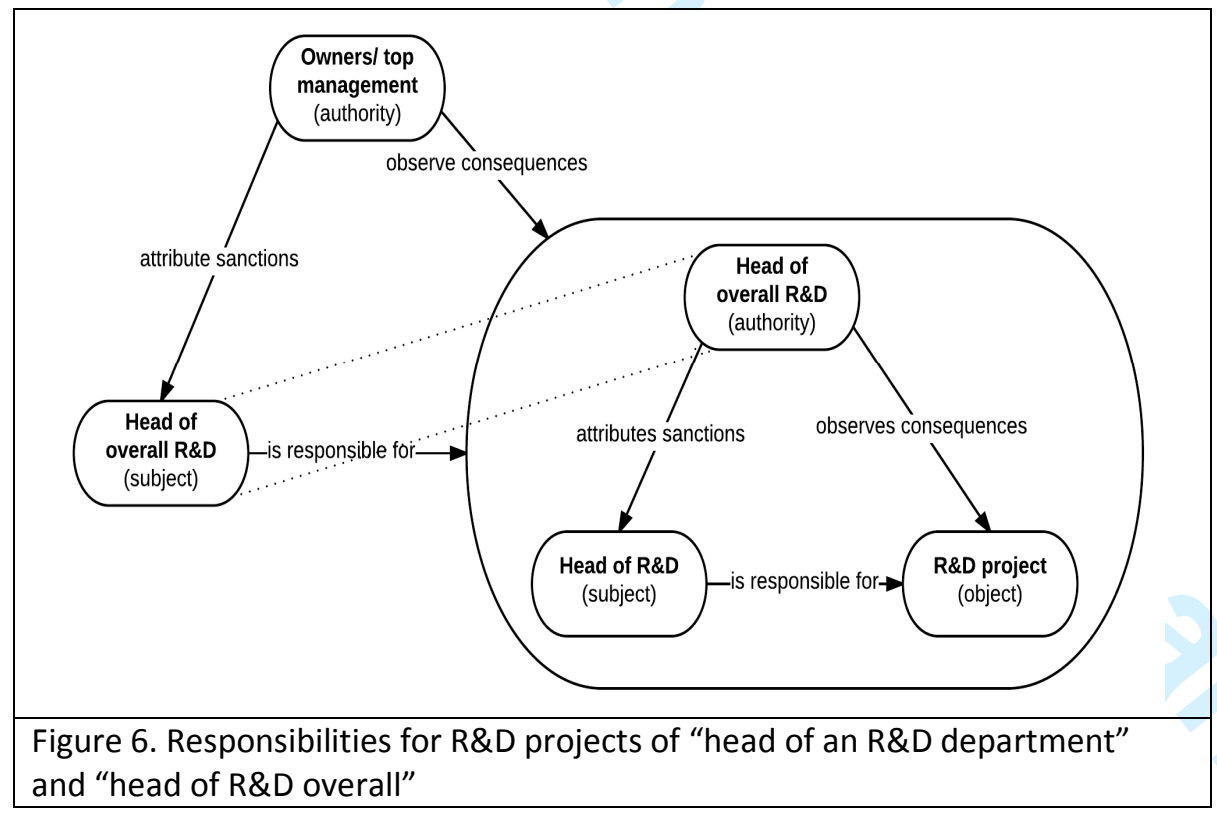

The "head of overall R\&D department" in this case is his line manager and therefore the authority in the responsibility relationship (see figure 6 above). The "head of the overall R\&D department" in turn is responsible for such objects as the "R\&D department", "overall research" and "the overall research agenda". Likewise, in AGE-Comp the CEO functions both as a subject and an authority in responsibility relationships that have "R\&D project" as an object. Here, the CEO then has a 
responsibility both as a subject for the progressing of R\&D projects and as an authority supervising them.

Further connections between responsibilities emerged due to actors being part of overarching collective actors. Of the 37 actors that emerged from the data, 14 represent individual persons, while 23 represent collective actors (composed of multiple individuals). All of the individual actors are in turn a member of (one or more) collective actors. This way responsibility attributed to a collective actor is further distributed to the individual actors that make up the collective entity. In CREA-Corp, for example, the actor "R\&D co-worker" is a member of the actor "R\&D department". The co-worker then, can be attributed (co-)responsibility for (some of) the responsibilities that are attributed to the $R \& D$ department as a whole. What is more, also some of the collective actors are part of an overarching collective actor. For example, in CREA-Corp, the "R\&D department" and the "marketing department" are part of the actor "company". Again, the relations between actors reflect the management structure of the company: an R\&D co-worker is part of the R\&D department, which in turn is part of the company. In a similar vein, while the "CTO" as an individual actor in AGE-Comp is a member of the collective actor "IT department", at the same time "IT department" is a division of another collective actor, namely "company". Hence, some of the responsibilities that are attributed to the company as a whole are also attributed to either the IT department as a collective actor or the CTO as an individual actor. These connections between actors, therefore, inform how responsibilities are distributed, for example, how it is distributed from the top-level to individuals, across the company.

The reappearance of actors across different relationships and functioning as different types of elements within the relationships is representative for the interrelatedness of responsibility relationships that are constitutive of the network of responsibilities. This interrelatedness represents the way different responsibilities affect each other: they may be conflicting, but also mutually reinforcing each other. For responsibilities to be effective in stimulating desired behaviour of actors, alignment of responsibilities, therefore, is required.

\section{Engaging External Actors}

Apart from constituting connections between responsibilities, actors can also be indicative of activities taking place that are relevant to RRI. Engaging with stakeholders and the general public is included as an essential characteristic of RRI in all accounts of RRI (see, for example, Owen et al. 2013; Von Schomberg 2011). The appearance of external actors in the elements of responsibility relationships, therefore, may signal responsibilities being relevant to RRI.

For both companies, seven of the actors that emerged from the data are not part of the company but are located externally. For example, the actors "industrial/client" and "university" for CREA-Corp and "care professionals" and "elderly people" in AGE-Comp are not part of the company but have nonetheless responsibilities for objects that are of relevance to the company. In CREA-Corp, for instance, industrial clients are regarded as important contributors in setting requirements for the development of (new) products, while customers are engaged by the marketing department to provide feedback and suggest new ideas on (new) products. Similarly, in AGE-Comp, apart from-an internal evaluation team dedicated to evaluating R\&D projects and new services, external peerreviewers are engaged to assess the company's innovative initiatives.

By including external actors and their demands in their R\&I process, external parties such as the "market" or "elderly people" are attributed (co-)responsibility for objects residing within the company, for instance, the object "research agenda". Furthermore, external actors, such as "society" and the "market", function as an authority in different responsibility relationships overviewing whether norms are being met and attributing sanctions accordingly. For example, as an authority, the "market" expresses its approval or dislike of products or services by either purchasing or not. 
Therefore, when including concerns for the societal impact of their R\&I, companies depend on external actors taking their related responsibilities, setting relevant norms and acting as an authority.

\section{Discussion}

The main purpose of this paper is to illustrate the theory of networks of responsibility as a tool to describe responsibility ascriptions in R\&I practice in order to assess their alignment to demands set by RRI. This section; therefore starts, by discussing the application of the proposed theory and methodology of the study, followed by a discussion of the findings, first in terms of the responsibility relationships that emerged from the data and second in terms of the possibilities of implementing characteristics of RRI in practice.

\subsection{Application of Theory and Methodology}

The analysis of the data surfaced 68 responsibility relationships. Moreover, the analysis of the different aspects of responsibility provided a way to describe and render accessible the interdependence and interrelatedness of the different responsibility relationships. However, not all components of responsibility, especially norm and authority, could be identified or extrapolated from the data for each relationship. These blanks found among the components are either the result of a lack of data or of these components actually not being known, or articulated in the companies. In addition, some of the components that did emerge are formulated in a way that lacks specificity. It will be of interest for further research to reflect on plausible reasons for this possible data inadequacy. Some indicative suggestions are listed here:

First, a reason for this could be the limitation of the data gathering methodology devised for the study. For example, by aligning the interview scheme more closely to the theoretical model, a more comprehensive account of the responsibilities within the R\&I processes could be attained.

Second, another possible explanation could be that there are actually responsibility gaps or unclarities surrounding responsibilities within the $R \& \mid$ processes of the companies studied. This could mean that for certain tasks or (sub-)processes within the R\&I processes it is unclear who is responsible for what, and/or what norm applies, and/or what authority is in place to assess/sanction this. The data, for example, did not provide insight into what norms apply to foresight exercises executed by people in CREA-Corp. This means it is unclear when outcomes of foresight are adequate or not. Moreover, it is not clear from the data what authority is in place to assess whether the norm is being met and sanction when the norm is not abided to.

This leads to a third reason, namely that the way responsibility is understood in R\&I practices may divert from how it is conceptualised in the theory of responsibility applied here. As was to be expected, in most instances when interviewees talked about responsibilities, these responsibilities were discussed in terms of (formal) job descriptions and related tasks. These responsibilities must be understood as "role" responsibilities, i.e. responsibilities stemming from an assigned role or task within an organisation. Although some of the aspects of responsibility outlined in the theory were implied by the interviewees, this was done less rigorously or more casually than outlined in the theoretical model.

In addition, because the majority of the responsibilities that emerged were formal, task-related responsibilities, informal responsibilities, for example, reflecting moral norms held by an actor, were largely left out the analysis. These responsibilities, however, may also be of relevance when assessing responsibilities guiding the behaviour of actors within $R \& I$ processes. 


\subsection{Connections between Responsibilities}

As was predicted during the discussion of the conceptual framework in section 2, reoccurring elements across responsibilities that emerged from the data constituted relationships and ultimately networks of responsibilities. Overall the elements accounted for five types of connections between responsibilities.

First, subjects came forward that have multiple responsibilities, either by being related to several objects or by having multiple sets of norms for one object. For example, the "head of the overall R\&D department" is subject in a range of responsibility relationships with objects such as R\&D departments, overall research, and external partnerships (see figure 5).

Second, objects surfaced that were implicated in multiple responsibility relationships and therefore were related to different norms and/or subjects. For example, "R\&D product requirements" is an object in different responsibility relationships for instance with "industrial client" and "R\&D project" as subjects.

These first two types of connections entail responsibility relationships that are either working together towards a shared goal but can also lead to conflicts, for example, when conflicting norms apply to a single object. To ensure that a set of related responsibilities realise an overall aim such as attaining societal acceptable and desirable consequences of R\&l, these responsibilities need to be brought into alignment with each other. For instance, upon developing a software platform to monitor the health conditions of elderly people, the demands of the elderly, such as accessibility and privacy, need to be aligned to the demands of investors and shareholders. When such demands are put forward by different norms or objects of responsibility, they may conflict with each other at some point. For instance, a tension may arise between the privacy of the elderly, and an increase in their health conditions by monitoring them constantly. Such conflicts can, for instance, be resolved by making trade-offs in the design of the implied technology (van den Hoven et al. 2011) or by creating a win-win situation via institutional reforms (Beckmann et al. 2014).

Third, norms were found that function in other relationships as an object. For instance, the "Company framework" of CREA-Corp functions as a norm in six responsibility relationships but is an object of responsibility in three relationships with "co-workers" and the "company" as its subjects (see figure 4).

From this third type of connection, it follows that actors within the companies need to reflect on norms, such as the company framework or privacy by design criteria, as part of attributing norms to responsibility relationships. CREA-Corp was also involved in working on future legislation. This may be a prerogative of large companies. In addition, for some responsibilities, the companies had less influence over the norms that its subjects had to adhere to, for example, when they were set by the market or legislators. In these cases, the responsibility relationships depict a dependence of the company on external actors. This calls for alignment of interdependent responsibilities of actors within and outside the company.

Fourth, subjects emerged from the data that function both as an authority and as an object in different responsibility relationships. This is complicated to analyse in industry, where departments doing the same things (e.g., managing R\&D projects) have different names, like R\&D management, innovation management, business development, etc. (Maier, 2014). Hence, the "head of the overall $R \& D$ department" is both a subject and an authority in different relationships. In the same manner, "R\&D project" functions as an object in five relationships and a subject in others.

Fifth, connections between responsibilities were established by collective actors composed of individual or smaller collective actors. For example, the R\&D department consists of co-workers 
whose aggregated individual responsibilities account for the collective responsibility of the department.

These last two types of connections mirror the division of tasks and the management structure of the companies. They enable understanding how responsibilities of collective actors are distributed to and divided among underlying smaller collective actors and ultimately to individual persons. This way, these relations prompt reflecting on how responsibility for objects or norms is shared among different individuals. Especially in large companies such as CREA-Corp, where collective actors consist of many persons, reflection is needed to establish who is responsible for what. RRI as metaresponsibility then entails dealing with emergent ambiguities as to prevent the so-called "the problem of many hands", i.e. the inability to establish accountability due to the number of subjects involved, from occurring (see, for example, van de Poel et al. 2011). Moreover, being a multinational corporation, actors of CREA-Corp may be spread over multiple countries and therefore have to deal with multiple legislations and cultures. In CREA-Corp, for example, this is dealt with by aligning norms from different countries to each other by following the standard of the country with the strictest rules.

\subsection{Characteristics of RRI in Practice}

During the interviews, both interviewees at CREA-Corp indicated that doing R\&I "in a responsible way" already is required and the default standard in the day-to-day practice of Western companies. However, at the same time, the interviewees stated that they were not familiar with the RRI discourse. Their interpretation of doing R\&I in a responsible manner resonates with their intuitive understanding of the concept of RRI and similar terms they are familiar with such as "responsible development" and CSR. To the interviewees, RRI means in the first place compliance with legal and social standards, which is needed to qualify for doing business.

Moreover, interviewees of both companies indicated that there is no tension between business (profit) and societal demands. To them, societal demands translate into social and legal standards, and into product requirements. Complying with standards and incorporating customer demands then amounts to a win-win situation for the company and its customers as it enables the company to bring products to the market that are desired by society. Meeting social and market demands, therefore, are not at odds with each other.

Although compliance with standards obviously is part of it, the aspirations set in the RRI discourse go well beyond this. The framework of RRI suggested by Owen et al. (2013), for instance, requires R\&I to have a collective and continuous commitment to be anticipatory, reflective, deliberative and responsive. The analysis did surface practices that could be interpreted as characteristics of RRI, even though they were not framed or intended as such by the companies.

Actors within CREA-Corp, for example, have responsibilities to do foresight, gauge the mood of the public, and to go beyond market standards. For AGE-Comp responsibilities emerged that implied attending to the needs of elderly people and safeguarding the privacy of users by deploying "Privacy by design". Additionally, both companies engaged with external actors to establish requirements and norms to their R\&I processes. As such, from a practical point of view, the proposed framework of networks of responsibility is highly aligned with one of the demands set by RRI, namely engagement. In essence, effective networks of responsibility enable effective stakeholder engagement, subsequently better-organized projects, products, and services. Hence, the proposed framework can be beneficial for companies from different perspectives.

Apart from currently displaying characteristics of RRI, objects and norms also may signal opportunities for further implementation of RRI within the companies. For example, in CREA-Corp the object "stage gating" represents the way R\&I processes are currently being managed. It involves 
Also, RRI could be incentivized via norms that are not set by the company itself, but that are attributed by actors who are external to the company. As indicated above, norms and objects of responsibilities of actors within the company may be imposed by external actors, such as customers and legislators. Elsewhere it has been suggested that RRI should be (and sometimes indeed already is) in "EU norms" and "treaties" (Von Schomberg 2013; Lee \& Petts 2013). This way, external actors may provide reasons and motivations for companies to implement RRI.

Objects and norms found in current responsibility relationships, however, do not just represent a potential for implementing RRI. They may also pose a threat to it. For example, as was to be expected in industry, an important object and norm that surfaced in the data analysis is "market success" or "company success". In the literature on RRI, it is suggested that there is a tension between the market and RRI's aim to address societal consequences. Von Schomberg (2013), for example, argues that the market by itself does not account for externalities it produces, such as environmental impacts. Market success alone, therefore, does not drive businesses to produce societally desirable consequences. Traditionally, this failure to address externalities is remedied via legislation (Von Schomberg 2013; Lee \& Petts 2013). This is confirmed by the interview data collected. It states that within the companies there is no tension between business (profit) and societal demands as societal demands are translated into social and legal standards, and thereby into product requirements.

Nonetheless, it is argued in the literature that legislation alone is not sufficient due to its inherent limitations such as attribution of liability for unforeseen consequences (Von Schomberg 2013; Lee \& Petts 2013). Governance, such as RRI, is needed to remedy deficits of market regulation. Meeting current legislation then would not suffice as RRI. The examples discussed above, such as being involved in creating future legislation and gauging public moods, nevertheless, can also be regarded as going beyond legislation. Moreover, going beyond or ahead of current standards, whether they are de-facto, voluntary or mandatory, is viewed by the companies as a way to differentiate themselves from their competitors. Setting more stringent standards for products in compliance with societal desires then does entail a strategic advantage over competing products.

The involvement of companies in standardisation is further motivated by it presenting a means to influence regulation according to their interests (Blind \& Mangelsdorf 2016). Involvement not only enables companies to anticipate and influence the contents of future standards but even may prevent standards from becoming mandatory, for example, by becoming (part of) formal regulation. In line with RRI, to ensure company interests do not conflict with societal interests, it then is recommended to have a balanced stakeholder engagement standardisation processes (cf. Blind \& Mangelsdorf 2016). 
Also, demanding companies to implement measures of RRI may be perceived as presenting an extra burden to R\&I organisations and therefore raise their resistance (Fisher \& Rip 2013; Stilgoe et al. 2013). Currently, societal considerations in place within the companies are regarded by the interviewees as contributing to the commercial interests of the companies. However, progressively furthering such measures may at a certain point diminish the companies' competitiveness when resources are spent on activities that do not contribute to meeting market demands. A way to consider RRI measures is through CSR, which is brought to life through linking innovation activities with an active stakeholder management (Maier et al., 2016).

While recognising that CSR is a company collective responsibility, we can argue that some roles are able to act as RRI principles within the company, across the corporate structures and processes, and linking to broader innovation activities. In principle, CSR has many overlaps with RRI principles. For example, CSR governance links to RRI sustainability principles, CSR stakeholder engagement has similarities with RRI inclusion principles, CSR disclosure refers to RRI responsiveness principle, and CSR social performance is mapped onto the RRI sustainability, ethical acceptability, and social desirability principles (latridis \& Schroeder 2016). The result of this is an important implication for the CSR-RRI relationship in which, by having a responsibility set, companies are able to develop a CSR strategy, subsequently implement RRI principles. Therefore, mainstreaming RRI among companies and supporting the uptake of CSR on their part, will have a major impact on the overall responsibility, sustainability accounting, and inclusiveness of responsible economic development in companies. This development from CSR areas to RRI principles, and then to innovation management actions will enable companies to embed RRI in value creation and company business development.

The conceptual framework developed in this paper contributes to further enabling CSR and accounting practices by providing detailed insight into the responsibilities and their constitutive elements such as objects and norms, and the way they are related within organisations. This insight can increase transparency and hence compliance with CSR and (sustainability) accounting standards within businesses (Cf. Adams \& Larrinaga-González 2007).

\section{Conclusion}

We started by framing RRI as a meta-responsibility aimed at shaping, maintaining, developing, coordinating and aligning lower level responsibilities and processes. This, in turn, called for an (ethical) reflection on current responsibility ascriptions in R\&I practice. Building on extant literature on responsibility, a theoretical model was proposed in which responsibility relationships are depicted as forming a network to do justice to their interrelatedness and interdependence. To illustrate the suitability of the model for R\&I in an industry setting, an explorative study was conducted.

Analysing two innovative companies surfaced 68 responsibility relationships involving a range of different objects, subjects, authorities, and norms. By describing overlaps in objects, subjects, and other aspects of relationships, the theoretical model proved adequate in untangling and displaying interrelatedness of responsibilities. However, not all aspects of responsibility as outlined in the theoretical model could be extracted from the interview data for every responsibility relationship. Three possible reasons for failing to deduce all responsibility aspects were suggested:

1. Limitations of the methodology used to map responsibilities.

2. Differences in interpretation of responsibility between R\&I practice and theoretical model used.

3. The existence of responsibility gaps and or lack of clarity about responsibilities within R\&I processes studied.

The first two reasons signal a possible discrepancy between the approach used and R\&I practice. Further development of the proposed approach will require looking into these two reasons. If the 
last reason is shown to be relevant, this would provide possible starting points for the implementation of RRI. Following RRI as a meta-responsibility, it is desirable that responsibility relations are in place and well understood in order to be able to maintain, develop and align them.

Overall, the network of responsibilities theory allowed us to identify elements and connections of responsibilities within the two companies. Responsibilities proved to be widely connected and entangled. Especially within the organisation of CREA-Corp, this complexity was further increased by large collective actors that distribute responsibility to its underlying (individual) actors. The size of some of the actors involved, but also the need to consider on-going responsibilities tied to the core business of a company, sets RRI in industry apart from publicly funded research. By incorporating existing responsibilities and emphasising the need to align these alongside introducing novel elements to them, makes RRI as a meta-responsibility especially suited for RRI in industry. What is more, the network theory supports surfacing elements of responsibility that allow singling out responsibilities that are of relevance to RRI. Both elements of responsibility that already display or potentially support implementing characteristics of RRI come forward, as well as possible threats that may raise resistance to do so. In the two companies, for example, CSR or "Privacy by design" already were being implemented, next to commercial norms and objects such as having a market share and satisfying customers' needs. Also, elements that emerged in the analysis displayed a dependence on external actors, such as the market, clients or legislators. In realising demands of RRI, the companies sometimes then rely on external actors, for example by setting standards or articulating requirements. RRI as a meta-responsibility acknowledges these existing responsibilities of companies and external actors, and suggests developing these further by both internal and external actors in mutual alignment, as a prerequisite to attaining societal acceptable and desirable R\&I.

The key theoretical contribution to knowledge that this paper makes is the development of a theory of RRI as a meta-responsibility that can govern existing networks of responsibilities. This theoretical approach is important because it offers a way to conceptualise RRI that goes beyond the current discourse while at the same time allowing scholars to draw on existing theories and views. By offering a detailed description of and reflection on the elements of existing responsibility relationships and their interconnections, it enables further substantiating what RRI means to actors in R\&I practice. It asks existing theories and approaches to consider how existing responsibilities will be affected by them and how new (co-)responsibilities will be distributed among the different R\&I actors. And, importantly, RRI as a meta-responsibility also raises the question how these different responsibilities are aligned with each other in order to meet the overall societal goals. This paper goes beyond the theoretical account and demonstrates its validity using two empirical case studies.

This important theoretical novelty of the paper opens the door to more exciting research. To further the development of the networks approach, it is recommended that theories and approaches associated with RRI are considered in the analysis, for example, the framework of RRI by Owen et al. (2013). This opens up the further exploration of possibilities for the substantiation of elements of responsibility (objects, subjects, norms, etc.). Additionally, further studies into the application of the theory should be broadened to also include informal responsibility relationships. In the current investigation, mainly formal, task responsibilities emerged from the data. To remedy this, the line of questioning may be broadened, further subjects of inquiry may be included, and additional data gathering methods may be deployed, such as participant observation.

In this paper, we specifically focussed on RRI in industry. Apart from its clear links with CSR in general (see, for example, latridis \& Schroeder 2016 and Pavie et al. 2014), this is warranted because RRI affects the field of sustainability accounting as well. Structurally innovating the governance of R\&l, RRI expands the dimensions of societal accountability (see, for example, Schwartz \& Carroll 2003 and Dahlsrud 2008) by introducing a novel or broadening existing responsibilities of innovative companies. As one of the pivotal societal aspects driving it (von Schomberg 2013, European 
Commission 2014 and Strand et. al 2015), sustainability will be (part of) the object or norm in many of these responsibilities. As a consequence, RRI may function as a driver for sustainability reporting (Dienes et al. 2016), and enhance accountability for their sustainability performance (Adams \& Larrinaga-González 2007). At the same time, sustainability accounting and reporting provide effective means supporting the implementation of RRI within companies. In this paper ${ }_{L}$ we could only touch on these important questions of the relationship between RRI and sustainability to a limited degree. Further research should explore them in more detail. It will be particularly interesting to focus on questions of sustainability accounting and how this may reflect work on RRI in financial industries.

To further explore how RRI and sustainability accounting can mutually reinforce each other it is worth investigating how responsibilities can be linked to specific information needs and the collection of particular types of information. Also, in further studies, more emphasis should be placed on possible threats and conflicts that may arise within the networks of responsibilities, and how these can be dealt with. And lastly, to draw a clearer picture of the networks across cultures and types of organisations, the qualitative approach used for this study should be complemented by a quantitative approach that allows gathering data from different industries, companies of various sizes, and locations, amongst others.

RRI sets an ambitious agenda to ensure a more social and ethical R\&I. Much work is still needed to bridge the gap between these theoretical and political aspirations and daily R\&I practice, especially in non-academic contexts such as industry. By offering a novel way to understand and untangle the complexity of responsibility relationships, the idea of RRI as a meta-responsibility governing existing networks of responsibility model offers a promising approach that provides a basis for this endeavour.

\section{References}

Adams, C.A. \& Larrinaga-González, C., 2007. Engaging with organisations in pursuit of improved sustainability accounting and performance. Accounting, Auditing \& Accountability Journal, 20(3), pp.333-355.

Albelda, E., 2011. The role of management accounting practices as facilitators of the environmental management: Evidence from EMAS organisations. Sustainability Accounting, Management and Policy Journal, 2(1), pp.76-100.

Beckmann, M., Hielscher, S. \& Pies, I., 2014. Commitment Strategies for Sustainability: How Business Firms Can Transform Trade-Offs Into Win-Win Outcomes. Business Strategy and the Environment, 23(1), pp.18-37.

Blind, K. \& Mangelsdorf, A., 2016. Motives to standardize: Empirical evidence from Germany. Technovation, 48-49, pp.13-24.

Boroush, M., 2010. National patterns of R\&D resources: 2008 data update. Data Brief, National Science Foundation (NSF 10-314). Available at: http://www.dic.com.ua/statistics/nsf10314/pdf/nsf10314.pdf [Accessed October 30, 2013].

Brem, A. \& Ivens, B.S., 2013. Do frugal and reverse innovation foster sustainability? Introduction of a conceptual framework. Journal of Technology Management for Growing Economies, 4(2), pp.31-50.

Broadbent, S., Dewandre, N., Ess, C., Floridi, L., Ganascia, J.G., Hildebrandt, M., Laouris, Y., Lobet-Maris, C., Oates, S., Pagallo, U., Simon, J., Thorseth, M. \& Verbeek, P.P., 2013. The Onlife Initiative, Brussels: European Commission.

Burritt, R.L. \& Schaltegger, S., 2010. Sustainability accounting and reporting: fad or trend? Accounting, Auditing \& Accountability Journal, 23(7), pp.829-846.

Butler, T., 1998. Towards a hermeneutic method for interpretive research in information systems. Journal of Information Technology (Routledge, Ltd.), 13(4), p.285-300.

Cagnin, C., Amanatidou, E. \& Keenan, M., 2012. Orienting European innovation systems towards grand challenges and the roles that FTA can play. Science and Public Policy, 39(2), pp.140-152. 
Chen, W. \& Hirschheim, R., 2004. A paradigmatic and methodological examination of information systems research from 1991 to 2001. Information Systems Journal, 14(3), pp.197-235.

Christ, K.L., Burritt, R. \& Varsei, M., 2016. Towards environmental management accounting for trade-offs. Sustainability Accounting, Management and Policy Journal, 7(3), pp.428-448.

Dahlsrud, A., 2008. How corporate social responsibility is defined: an analysis of 37 definitions. Corporate Social Responsibility and Environmental Management, 15(1), pp.1-13.

Dienes, D., Sassen, R. \& Fischer, J., 2016. What are the drivers of sustainability reporting? A systematic review. Sustainability Accounting, Management and Policy Journal, 7(2), pp.154-189.

European Commission, 2011a. A renewed EU strategy 2011-14 for Corporate Social Responsibility (No. $\operatorname{COM(2011)~} 681$ final), Brussels. Available at: http://ec.europa.eu/enterprise/policies/sustainablebusiness/files/csr/new-csr/act_en.pdf [Accessed October 30, 2013].

European Commission, 2010. COM(2010) 2020: Europe 2020 - A strategy for smart, sustainable and inclusive growth, Available at: http://ec.europa.eu/eu2020/ [Accessed January 12, 2011].

European Commission, 2011b. Commission's Recommendation to the Member States on Responsible Research and Innovation, European Commission. Available at:

http://ec.europa.eu/governance/impact/planned_ia/docs/2010_rtd_012_responsible_research_innovation_en .pdf [Accessed November 6, 2012].

European Commission, 2014. Rome Declaration on Responsible Research and Innovation in Europe, European Commission, Rome. Available at:

http://ec.europa.eu/research/swafs/pdf/rome_declaration_RRI_final_21_November.pdf [Accessed February 6, 2015].

Fischer, J.M., 1999. Recent Work on Moral Responsibility. Ethics, 110(1), pp.93-139.

Fisher, E., Mahajan, R.L. \& Mitcham, C., 2006. Midstream Modulation of Technology: Governance From Within. Bulletin of Science, Technology \& Society, 26(6), pp.485-496.

Fisher, E. \& Rip, A., 2013. Responsible Innovation: Multi-level dynamics and soft intervention practices. In Owen, R., Heintz, M. \& Bessant, J. (Eds.), Responsible Innovation: Managing the Responsible Emergence of Science and Innovation in Society, Wiley, Chichester, UK, pp. 165-183.

Floridi, L. \& Sanders, J.W., 2004. On the Morality of Artificial Agents. Minds and Machines, 14(3), pp.349-379.

French, P.A. (Ed.), 1972. Individual and Collective Responsibility: Massacre at My Lai. 1st edition, Schenkman Publishing Co., Cambridge, Massachusetts.

French, P.A., 1979. The corporation as a moral person. American Philosophical Quarterly, 16(3), pp.207-215.

Geoghegan-Quinn, M., 2012. Responsible Research and Innovation. Europe's ability to respond to societal challenges, European Union. Available at: http://ec.europa.eu/research/science-society [Accessed November 22 2012].

Georghiou, L., 2008. The Handbook of Technology Foresight: Concepts and Practice, Edward Elgar Publishing Ltd., Cheltenham, UK; Northampton, MA.

Glodman, A.I., 1999. Why Citizens Should Vote: A Causal Responsibility Approach. In Paul, E. F. , Miller, F. D. M. \& Paul, J. (Eds.), Responsibility, Cambridge University Press, Cambridge, pp. 201-217.

Gray, R., 2010. A re-evaluation of social, environmental and sustainability accounting: An exploration of an emerging trans-disciplinary field? Sustainability Accounting, Management and Policy Journal, 1(1), pp.11-32.

Grinbaum, A. \& Groves, C., 2013. What is "Responsible" about Responsible Innovation? Understanding the Ethical Issues. In Owen, R., Heintz, M. \& Bessant, J. (Eds.), Responsible Innovation: Managing the Responsible Emergence of Science and Innovation in Society, Wiley, Chichester, UK, pp. 119-142.

Grunwald, A., 2011. Responsible innovation: bringing together technology assessment, applied ethics, and STS research. Enterprise and Work Innovation Studies, 7, pp.9-31.

Grunwald, A., 2012. Responsible Nanotechnology. Philosophy and Ethics, Taylor \& Francis Group, LLC, Boca Raton, FL. 
Grunwald, A., 2009. Technology Assessment: Concept and Methods. In Meijers, A. (Ed.), Philosophy of Technology and Engineering Sciences: 9. North Holland, Amsterdam, pp. 1103-1146.

Grunwald, A., 2014. The hermeneutic side of responsible research and innovation. Journal of Responsible Innovation, 1(3), pp.274-291.

Hart, H.L.A., 1968. Punishment and Responsibility: Essays in the Philosophy of Law, Clarendon Press, Oxford.

Heersmink, R. \& Oosterlaken, I., 2009. Responsible Innovation An International Inventory of Research Activities and Knowledge Dissemination Pathways, Delft University of Technology, Delft.

Hine, D. \& Carson, D., 2007. Innovative methodologies in enterprise research, Edward Elgar Publishing, Cheltenham, UK ; Northampton, MA.

van den Hoven, M.J., 2013. Value Sensitive Design and Responsible Innovation. In Owen, R., Heintz, M. \& Bessant, J. (Eds.), Responsible Innovation: Managing the Responsible Emergence of Science and Innovation in Society, Wiley, Chichester, UK, pp. 75-84.

van den Hoven, M.J., Lokhorst, G.J. \& van de Poel, I., 2011. Engineering and the Problem of Moral Overload. Science and Engineering Ethics, 18(1), pp.143-155.

latridis, K. \& Schroeder, D., 2016. Responsible Research and Innovation in Industry: The Case for Corporate Responsibility Tools, Springer, Dordrecht, the Netherlands.

Jacob, K., van den Hoven, J.M.J., Nielsen, L., Roure, F., Rudze, L, Stilgoe, J., Blind, K., Guske, A-L., Martinez Riera, C., 2013. Options for Strengthening Responsibile Research and Innovation. Report of the Expert Group on the State of Art in Europe on Responsible Research and Innovation, Luxembourg: European Commission.

Jonas, H., 1984. The Imperative of Responsibility: In Search of an Ethics for the Technological Age, University of Chicago Press, London; Chicago.

Kastenhofer, K., 2011. Risk Assessment of Emerging Technologies and Post-Normal Science. Science, Technology \& Human Values, 36(3), pp.307-333.

Klein, H.K. \& Myers, M.D., 1999. A set of principles for conducting and evaluating interpretive field studies in information systems. MIS Quarterly, 23(1), pp.67-93.

Lee, R.G. \& Petts, J., 2013. Adaptive Governance for Responsible Innovation. In Owen, R., Heintz, M. \& Bessant, J. (Eds.), Responsible Innovation: Managing the Responsible Emergence of Science and Innovation in Society, Wiley, Chichester, UK, pp. 143-164.

Lenk, H., 1997. Progress, Values, and Responsibility. Society for Philosophy and Technology, 2(3-4), pp.102119.

Lenk, H., 2006. What is Responsibility? Philosophy Now, 56(July/August), pp.29-32.

Lenk, H. \& Maring, M., 2001. Responsibility and Technology. In Auhagen, A. E. \& Bierhoff, H. W. (Eds.), Responsibility. The many faces of a social phenomenon. Routledge Research International Series in Social Psychology. Routledge, London; New York, pp. 257-277.

Martin, B.R., 2010. The origins of the concept of "foresight" in science and technology: An insider's perspective. Technological Forecasting and Social Change, 77(9), pp.1438-1447.

Miles, M.B. \& Huberman, A.M., 1994. Qualitative data analysis: an expanded sourcebook, Sage, Thousand Oaks; London; New Delhi.

Murphy, J., Parry, S. \& Walls, J., 2016. The EPSRC's Policy of Responsible Innovation from a Trading Zones Perspective. Minerva, 54(2), pp.151-174.

Murray, A., Haynes, K. \& Hudson, L.J., 2010. Collaborating to achieve corporate social responsibility and sustainability?: Possibilities and problems, Sustainability Accounting, Management and Policy Journal, 1(2), pp.161-177.

Owen, R. Stilgoe, J., Macnaghten, P., Gorman, M., Fisher, E. \& Guston, D., 2013. A Framework for Responsible Innovation. In Owen, R., Heintz, M. \& Bessant, J. (Eds.), Responsible Innovation: Managing the Responsible Emergence of Science and Innovation in Society, Wiley, Chichester, UK, pp. 27-50. 
Owen, R. \& Goldberg, N., 2010. Responsible Innovation: A Pilot Study with the U.K. Engineering and Physical Sciences Research Council. Risk Analysis, 30(11), pp.1699-1707.

Owen, R., Macnaghten, P. \& Stilgoe, J., 2012. Responsible research and innovation: From science in society to science for society, with society. Science and Public Policy, 39(6), pp.751-760.

Pavie, X., Scholten, V. \& Carthy, D., 2014. Responsible Innovation : From Concept to Practice, World Scientific Publishing Company, New Jersey.

Patton, M.Q., 2002. Qualitative research and evaluation methods, Sage, Thousand Oaks; London; New Delhi.

Pellizzoni, L., 2004. Responsibility and Environmental Governance. Environmental Politics, 13(3), pp.541-565.

van de Poel, I. Nihlén Fahlquist, J., Doorn, N., Zwart, S.D. \& Royakkers, L.,, 2011. The Problem of Many Hands: Climate Change as an Example. Science and Engineering Ethics, 18(1), pp.49-67.

Ricoeur, P., 1992. Oneself as another, University of Chicago Press, London; Chicago.

Sardar, Z., 2010. The Namesake: Futures; futures studies; futurology; futuristic; foresight-What's in a name? Futures, 42(3), pp.177-184.

Scholten, V. E., \& Blok, V. 2015. Foreword: responsible innovation in the private sector. Journal on Chain and Network Science, 15(2), pp.101-105.

Schwartz, M.S. \& Carroll, A.B., 2003. Corporate social responsibility: A three-domain approach. Business Ethics Quarterly, 13(04), pp.503-530.

Siune, K., Markus, E., Calloni, M., Felt, U., Gorski, A., Grunwald, A., Rip, A., de Semir, V. \& Wyatt, S., 2009. Challenging Futures of Science in Society. Emerging trends and cutting-edge issues. Report of the MASIS Expert Group., European Commission.

Stahl, B. C. (2004). Responsible Management of Information Systems, Idea Group Publishing, Hershey; London.

Stahl, B. \& Brem, A., 2013. Spaces for Responsible Innovation in Entrepreneurship: A Conceptual Analysis. In Proceedings of the 2013 IEEE International Technology Management Conference \& 19th ICE Conference, IEEE, The Hague, pp.1-16.

Stahl, B.C., 2012. Responsible research and innovation in information systems. European Journal of Information Systems, (21), pp.207-211.

Stahl, B.C., Eden, G. \& Jirotka, M., 2013. Responsible Research and Innovation in Information and Communication Technology. Identifying and engaging with the ethical implications of ICTs. In Owen, R., Heintz, M. \& Bessant, J. (Eds.), Responsible Innovation: Managing the Responsible Emergence of Science and Innovation in Society, Wiley, Chichester, UK, pp. 199-218.

Stilgoe, J., Owen, R. \& Macnaghten, P., 2013. Developing a framework for responsible innovation. Research Policy, 42(9), pp.1568-1580.

Stohl, M. \& Stohl, C., 2010. Human rights and corporate social responsibility: Parallel processes and global opportunities for states, corporations, and NGOs. Sustainability Accounting, Management and Policy Journal, 1(1), pp.51-65.

Strand, R., Spaapen, J., Bauer, M., Hogan, E., Revuelta, G., Stagl, S., Paulo, L. \& Guimarães Pereira, A. et al., 2015. Indicators for promoting and monitoring Responsible Research and Innovation. Report from the Expert Group on Policy Indicators for Responsible Research and Innovation, European Commission, Luxembourg. Available at: https://ec.europa.eu/research/swafs/pdf/pub_rri/rri_indicators_final_version.pdf [Accessed November 29, 2015].

Strydom, P., 1999. The Challenge of Responsibility for Sociology. Current Sociology, 47(3), pp.65-82.

Sutcliffe, H., 2011. A report on responsible research \& innovation, Available at: http://www.matterforall.org/pdf/RRI-Report2.pdf [Accessed November 6, 2012].

Tilt, C.A., 2009. Corporate Responsibility, Accounting and Accountants. In Idowu, S. O. \& Leal Filho, W. (Eds.), Professionals' Perspectives of Corporate Social Responsibility. Springer Berlin Heidelberg, Berlin, Heidelberg, pp. $11-32$. 
Timmermans, J.F.C. \& Stahl, B.C., 2013. Annual Report on RRI 2013, FP-7 GREAT Project. Available at: http://www.great-project.eu/deliverables_files/deliverables05 [Accessed January 14, 2014].

Vincent, N.A., 2011. A Structured Taxonomy of Responsibility Concepts. In Vincent, N. A., van de Poel, I. \& van den Hoven, J. (Eds.), Moral Responsibility. Library of Ethics and Applied Philosophy. Springer, Dordrecht, pp. 15-35.

Vincent, N.A., van de Poel, I. \& van den Hoven, J., 2011. Moral Responsibility: Beyond Free Will and Determinism, Springer, Dordrecht.

Visser, W. , Matten, D., Pohl, M. \& Tolhurst, N. (Eds.), 2010. The A to Z of corporate social responsibility, Chichester, Wiley, West Sussex, UK.

Von Schomberg, R., 2013. A Vision of Responsible Research and Innovation. In Owen, R., Heintz, M. \& Bessant, J. (Eds.), Responsible Innovation: Managing the Responsible Emergence of Science and Innovation in Society, Wiley, Chichester, UK, pp. 51-74.

Von Schomberg, R., 2012. Prospects for Technology Assessment in a Framework of responsible research and Innovation. In Dusseldorp, M. \& Beecroft, R. (Eds.), Technikfolgen abschätzen lehren. Springer, Berlin; Heidelberg, pp. 39-61.

Von Schomberg, R. (Ed.), 2011. Towards Responsible Research and Innovation in the Information and Communication Technologies and Security Technologies Fields, Luxembourg: Publication Office of the European Union.

Wallace, R.J., 1998. Responsibility and the Moral Sentiments, Harvard University Press, Cambridge, Mass.

Walsham, G., 2006. Doing interpretive research. European Journal of Information Systems, 15(3), pp.320-330.

Walsham, G., 1993. Interpreting Information Systems in Organizations, John Wiley \& Sons, Chichester, UK.

Windolph, S.E., Harms, D. \& Schaltegger, S., 2014. Motivations for Corporate Sustainability Management: Contrasting Survey Results and Implementation. Corporate Social Responsibility and Environmental Management, 21(5), pp.272-285.

Wright, D., Gellert, R., Gutwirth, S.\& Friedewald, M., 2011. Precaution and privacy impact assessment as modes towards risk governance. In Von Schomberg, R. (Ed.), Towards Responsible Research and Innovation in the Information and Communication Technologies and Security Technologies Fields. Luxembourg: Publication Office of the European Union, pp. $83-97$.

Yin, R.K., 2009. Case Study Research: Design and Methods, Sage Publications, Thousand Oaks; London; New Delhi. 